\title{
Predictive criteria of insignificant prostate cancer: what is the correspondence of linear extent to percentage of cancer in a single core?
}

\author{
Athanase Billis ${ }^{1}$, Maisa M.Q. Quintal ${ }^{1}$, Leandro L.L. Freitas ${ }^{1}$, Larissa B. E. Costa ${ }^{1}$, Ubirajara Ferreira ${ }^{2}$ \\ ${ }^{1}$ Department of Anatomic Pathology, School of Medical Sciences, State University of Campinas (Unicamp), \\ Campinas, Brazil; ${ }^{2}$ Department of Urology (UF), School of Medical Sciences, State University of Campinas \\ (Unicamp), Campinas, Brazil
}

\section{ABSTRACT}

Objective: The aim of active surveillance of early prostate cancer is to individualize therapy by selecting for curative treatment only patients with significant cancer.

Epstein's criteria for prediction of clinically insignificant cancer in surgical specimens are widely used. Epstein's criterion "no single core with $>50 \%$ cancer" has no correspondence in linear extent. The aim of this study is to find a possible correspondence. Materials and Methods: From a total of 401 consecutive patients submitted to radical prostatectomy, $17(4.2 \%)$ met criteria for insignificant cancer in the surgical specimen. The clinicopathologic findings in the correspondent biopsies were compared with Epstein's criteria for insignificant cancer. Cancer in a single core was evaluated in percentage as well as linear extent in $\mathrm{mm}$.

Results: Comparing the clinicopathologic findings with Epstein's criteria predictive of insignificant cancer, there was 100\% concordance for clinical stage T1c, no Gleason pattern 4 or $5, \leq 2$ cores with cancer, and no single core with $>50 \%$ cancer. However, only $25 \%$ had density $\leq 0.15$. The mean, median and range of the maximum length of cancer in a single core in mm were $1.19,1$, and 0.5-2.5, respectively. Additionally, the mean, median, and range of length of cancer in all cores in mm were 1.47, 1.5, and $0.5-3$, respectively.

Conclusion: To pathologists that use Epstein's criteria predictive of insignificant cancer and measure linear extent in $\mathrm{mm}$, our study favors that "no single core with $>50 \%$ cancer" may correspond to $>2.5 \mathrm{~mm}$ in linear extent.

\section{ARTICLE INFO}

Key words:

Prostate; Biopsy, Needle

Adenocarcinoma; Prostatectomy;

Prostatic Neoplasms; Risk

Int Braz J Urol. 2015; 41: 367-72

Submitted for publication:

July 01,2014

Accepted after revision:

September 28,2014

\section{INTRODUCTION}

Due to widespread of PSA screening, an increasing number of T1c prostate carcinomas are diagnosed as well as the so-called clinically insignificant tumors. Many of these malignancies would most probably not have caused any symptoms during a man's lifetime if they had remained undiagnosed. This so-called overdiagnosis due to screening often results in overtreatment, subjecting men to unnecessary costly and invasive treatment with risk of important side effects (1). The aim of active surveillance of early prostate cancer is to individualize therapy by selecting for curative therapy only patients with significant cancer (2). The best possible selection of patients with prostate cancer with low risk progression is the main factor for a successful active surveillance. 
Epstein's criteria on biopsies for prediction of clinically insignificant cancer in the radical prostatectomy specimens are widely used $(3,4)$. The criteria include: clinical stage T1c, PSA density $\leq 0.15$, no Gleason score 4 or $5, \leq 2$ biopsy cores with cancer, and $\leq 50 \%$ cancer per core. An alternative measure to the latter criterion is to evaluate the maximum length in $\mathrm{mm}$ of cancer per core. A survey among pathologists showed that an estimate of the linear extent of cancer in a core was made by $81 \%$ (5). This assessment was most often given in millimeters for each core by 53\% followed by estimation of percentage of cancer in each core by 39\%.

Considering that a high number of pathologists evaluate tumor extent on biopsies in millimeters, which length in mm corresponds to $\leq 50 \%$ cancer per core when using Epstein's criteria? The aim of this study is to find this possible correspondence.

\section{MATERIALS AND METHODS}

This retrospective study was based on prostate specimens from 401 patients submitted to radical retropubic prostatectomy by one surgeon (UF). All biopsies and surgical specimens were reviewed by a senior uropathologist $(\mathrm{AB})$. The tumors were graded according to the 2005 International Society of Urological Pathology (ISUP) modified Gleason score values (6). After radical prostatectomy, serum PSA was drawn every 3 months during the first year, every 6 months during the second year, and annually thereafter. No patient of this series had radiotherapy or androgen manipulation before or after surgery. Total serum PSA was measured utilizing previous validated Immulite ${ }^{\circledR}$ PSA kit. Biochemical recurrence following surgery was considered as PSA $\geq 0.2 \mathrm{ng} / \mathrm{mL}$ with a second confirmatory level of PSA $>0.2 \mathrm{ng} / \mathrm{mL}$ according to recommendation of the American Urological Association (7). Patients without evidence of biochemical recurrence were censored at last follow-up. The present study was approved by the Institutional Committee of Ethics of our Institution.

The surgical specimens were step-sectioned at 3 to $5 \mathrm{~mm}$ intervals and totally embedded in paraffin. A mean of 32 paraffin blocks were processed and $6 \mu \mathrm{m}$ sections from each block were stained with hematoxylin and eosin. Each transverse section of the prostate was subdivided into 2 anterolateral and 2 posterolateral quadrants. Using the cone method, 8 sections from the bladder neck and 8 sections from the apex were obtained.

Positive surgical margin was defined as cancer cells in contact with the inked specimen surface. Extraprostatic extension was diagnosed whenever cancer was seen in adipose tissue and, in case of desmoplastic response, whenever a protuberance corresponding to extension of tumor into periprostatic tissue was seen. Seminal vesicle invasion occurred whenever there was involvement of the muscular coat. Tumor extent at radical prostatectomy was evaluated by a semiquantitative point-count method previously described (8). Briefly, drawn on a sheet of paper, each quadrant of the transverse sections contained 8 equidistant points. During the microscopic examination of the slides, the tumor area was drawn on the correspondent quadrant seen on the paper. At the end of the examination the amount of positive points represented an estimate of the tumor extent. A total of $\leq 10$ positive points (minimal tumor extent) correspond to $\leq 0.5 \mathrm{~cm}^{3}$ tumor.

We defined insignificant cancer in radical prostatectomy, patients with organ-confined tumor ( $\mathrm{p} \mathrm{T2}$ ), $\leq 0.5 \mathrm{~cm}^{3}$ tumor (minimal tumor extent), negative surgical margins, and Gleason score $\leq 6$. Several clinicopathologic findings of the patients were studied: age, race, clinical stage, preoperative serum PSA, weight of the prostate in surgical specimen, pathologic PSA density (serum PSA/weight of the prostate in surgical specimen); and, on the correspondent needle biopsies number of cores with cancer, maximum percentage of cancer in a single core, maximum length of cancer in a single core in $\mathrm{mm}$, length of cancer in all cores in $\mathrm{mm}$, and number of cores. Linear extent of carcinoma in mm was measured using a single Olympus (Olympus Optica Co., Ltd., Tokyo, Japan) micrometer eyepiece with a linear array. In cases of discontinuous foci $1 \mathrm{~mm}$ apart, the tumor was considered as continuous and the measure included $1 \mathrm{~mm}$. In discontinuous foci more than $1 \mathrm{~mm}$ apart, the final extent was the sum of the measures. 


\section{RESULTS}

From 401 consecutive patients submitted to radical prostatectomy over a period of 13.8 years, $17(4.2 \%)$ patients met criteria for insignificant cancer in the surgical specimens. The mean follow-up after surgery of these 17 patients was 81 months (median 79, range 32-148). All patients were clinical stage T1c and no patient during this period had biochemical recurrence. The mean and median age (range) was 61 and 64 (46-70) years. From the total of 17 patients, $12(70.6 \%)$ were Whites and 5 (29.4\%) were African-Brazilians. From the total of 17 needle biopsies, 12 were extended. The mean and median number of cores was 10 and 9 , respectively.

The clinicopathologic findings in these 17 patients are shown in Table-1. The mean, median and range of the maximum length of cancer in a single core in mm were $1.19,1$, and $0.5-2.5$, respectively. No core showed length of cancer $>2.5$ $\mathrm{mm}$.

Additionally, the mean, median, and range of length of cancer in all cores in mm was 1.47, 1.5 , and $0.5-3$, respectively. In no biopsy the length of cancer in all cores was $>3 \mathrm{~mm}$. Figure- 1 illustrates a focus of adenocarcinoma in a biopsy core; it measures $0.5 \mathrm{~mm}$ corresponding to $4.5 \%$ of the total linear extent of the fragment which measured $11 \mathrm{~mm}$.

In Table-2 we compare the clinicopathologic findings with Epstein's criteria on needle biopsy predictive of insignificant cancer in surgical specimens. The findings were concordant in $100 \%, 100 \%, 100 \%, 100 \%$, and $24 \%$ patients for stage T1c, no Gleason pattern 4 or $5, \leq 2$ cores with cancer, no core with $>50 \%$ cancer, and PSA density $\leq 0.15$, respectively.

\section{DISCUSSION}

In this novel approach we found that comparing the findings of 17 prostatectomy specimens with insignificant cancer, there was 100\% concordance with Epstein's predictive criteria on biopsies for clinical stage T1c, no Gleason pattern 4 or $5, \leq 2$ cores with cancer, and no core with $>50 \%$ cancer per core. The mean and median (ran-
Table 1 - Clinicopathologic findings on the correspondent needle biopsies of 17 patients submitted to radical prostatectomy with insignificant cancer in the surgical specimen.

\begin{tabular}{|c|c|}
\hline \multicolumn{2}{|c|}{ Preoperative PSA (ng/mL) } \\
\hline Mean \pm SD & $7.76 \pm 2.26$ \\
\hline Median & 7.3 \\
\hline Range & $4.4-12.30$ \\
\hline \multicolumn{2}{|c|}{ Pathologic PSA density } \\
\hline Mean $\pm S D$ & $0.19 \pm 0.06$ \\
\hline Median & 0.17 \\
\hline Range & $0.11-0.27$ \\
\hline \multicolumn{2}{|c|}{ Weight of the prostate $(g)$} \\
\hline Mean $\pm S D$ & $43.53 \pm 10.03$ \\
\hline Median & 45 \\
\hline Range & $26-60$ \\
\hline \multicolumn{2}{|c|}{ Number of cores with cancer } \\
\hline Mean $\pm S D$ & $1.41 \pm 0.51$ \\
\hline Median & 1 \\
\hline Range & $1-2$ \\
\hline \multicolumn{2}{|c|}{ Maximum length of cancer in a single core (mm) } \\
\hline Mean \pm SD & $1.19 \pm 0.63$ \\
\hline Median & 1 \\
\hline Range & $0.5-2.50$ \\
\hline \multicolumn{2}{|c|}{ Maximum length of cancer in a single core (\%) } \\
\hline Mean $\pm S D$ & $13.69 \pm 6.63$ \\
\hline Median & 12 \\
\hline Range & $4.5-25$ \\
\hline \multicolumn{2}{|c|}{ Length of cancer in all cores (mm) } \\
\hline Mean $\pm S D$ & $1.47 \pm 0.67$ \\
\hline Median & 1.5 \\
\hline Range & $0.5-3$ \\
\hline
\end{tabular}

ge) maximum length in a single core in mm was 1.2 and $1(0.5-2.5)$. No single core in the biopsy showed cancer length $>2.5 \mathrm{~mm}$. An additional finding was a maximum length not more than $3 \mathrm{~mm}$ considering the 2 cores.

A review article has stated that no optimal method is available but advises measurements of tumor burden being in millimeters as well as percentage terms (9). We consider that the correspon- 
Table 2 - Clinicopathologic findings on needle biopsy of 17 patients with insignificant cancer in comparison with Epstein's criteria predictive of insignificant cancer in surgical specimens.

\begin{tabular}{ll}
\hline Clinical stage T1C & $17 / 17(100 \%)$ \\
No Gleason pattern 4 or 5 & $17 / 17(100 \%)$ \\
$\leq 2$ cores with cancer & $17 / 17(100 \%)$ \\
No core with $>50 \%$ cancer & $17 / 17(100 \%)$ \\
PSA density $\leq 0.15$ & $4 / 17(23.53 \%)$ \\
\hline
\end{tabular}

dence we found in our study is important for pathologists who do not use percentage for evaluation of cancer extent. Using Epstein's criteria on biopsies to predict insignificant prostate cancer in the radical prostatectomy specimens, an alternative to the criterion "no core with $>50 \%$ cancer" is "no core with $>50 \%$ cancer and $>2.5 \mathrm{~mm}$ in linear extent".

Cancer length can be measured and reported in many ways but no optimum method exists for assessing tumor burden in prostate cores (10). The amount of cancer reported may affect eligibility for active surveillance programs. A survey among pathologists showed that most pathologists estimate cancer on biopsies as linear extent in $\mathrm{mm}$ and not in percentage (5). Among the arguments in favor of linear extent in $\mathrm{mm}$, is that percentage of core involvement is dependent on the length of the cores (11).

Millimetric measurements are preferable to percentages (e.g., 100\% of a $4 \mathrm{~mm}$ core is very different from a $100 \%$ of a $15 \mathrm{~mm}$ core) (5). Other advantage of using millimetric measurements is in fragmented specimens due to the fact that percent core involvement may vary with different core lengths.

A concern exists when there are two or more foci of cancer in a single core separated by benign intervening stroma. Currently, there is no consensus as to the optimal method for measuring discontinuous cancer on biopsy from one end to the other as opposed to "collapsing" the cancer by subtracting out the intervening benign prostate tissue (11-13). In this study only one core showed two foci $<1 \mathrm{~mm}$ apart. This case was considered as a single focus and the total linear extent of the tumor was $1.5 \mathrm{~mm}$.

The frequency of insignificant cancer in radical prostatectomy surgical specimens in our study was $4.2 \%$. Sengupta $S$ et al. found a frequency of

Figure 1 - Illustration of a focus of adenocarcinoma in a biopsy core measuring $0.5 \mathrm{~mm}$ and corresponding $4.5 \%$ of the total linear extent of the fragment which measured $11 \mathrm{~mm}$ (hematoxylin-eosin, 100x).

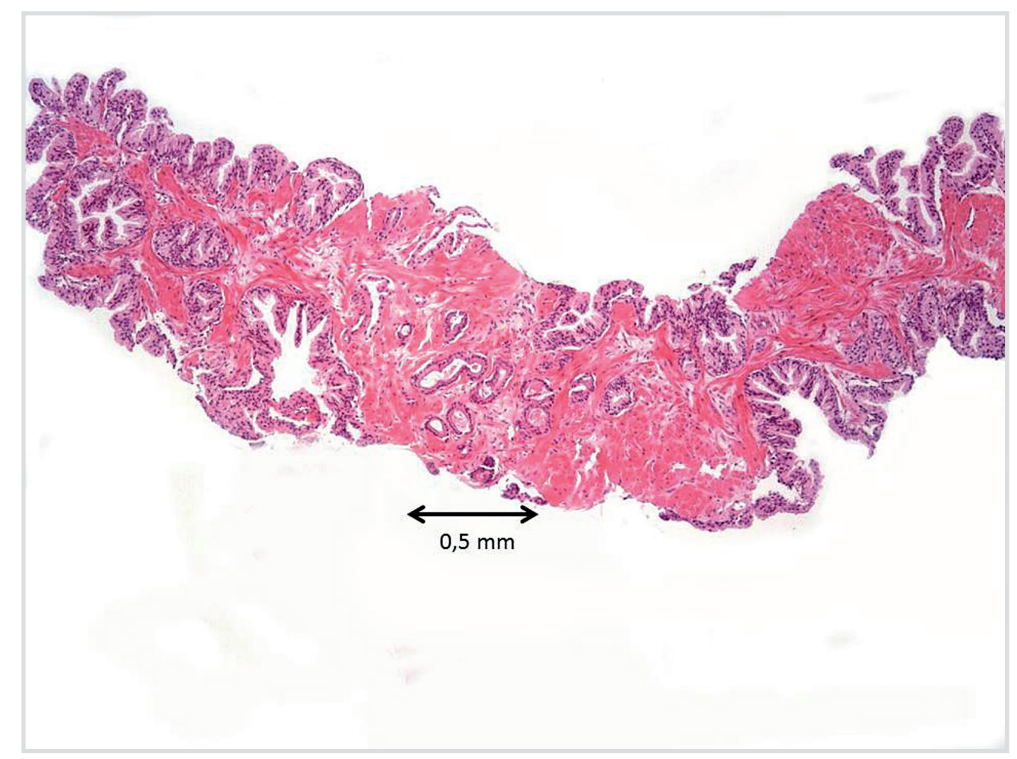


5.5\% (14), Augustin H et al. 5.8\% (15), and Loeb S et al. 2.6\% (16). No patient had biochemical recurrence in a mean follow-up period after surgery of 81 months (median 79, range 32-148). The clinicopathologic findings of these patients favor a very low risk cancer and could have been candidates for active surveillance.

The only discrepancy with Epstein's criteria in our findings was related to PSA density. The mean and median (range) was 0.19, 0.17 (0.11-0.27). According to our result, a cutoff for PSA density $\leq 0.15$ seems to be very restrictive. Most entry criteria for active surveillance consider PSA density $<15 \mathrm{ng} /$ $\mathrm{mL}$ but others, however, consider higher cutoffs (1, 15-22). The entry criteria for active surveillance in the PRIAS study include: clinical stage T1c-T2b, no Gleason pattern 4 or 5 , fewer than 3 positive cores, serum PSA $<10 \mathrm{ng} / \mathrm{mL}$, and PSA density $<0.20 \mathrm{ng} /$ $\mathrm{mL} / \mathrm{cm}^{3}$ (1). We must consider, however, that in our study PSA density was calculated by dividing preoperative PSA level by prostate weight in surgical specimen and in most studies the weight (volume) of the prostate is calculated by ultrasound. In spite of studies showing that the correlation between pathologic PSA density and actual PSA density using transrectal ultrasound is almost perfect $(3,23)$, these different measures may influence the results.

The serum PSA level is also variably considered in entry criteria for active surveillance.

It may be considered $<10 \mathrm{ng} / \mathrm{mL},<15 \mathrm{ng} /$ $\mathrm{mL}$, and even not considered as an entry criterion $(1,3,17,18,20,21)$. In our study the mean, and median (range) preoperative serum PSA value was 7.8, and 7.3 (4.5-12.30) ng/mL.

Some study limitations warrant discussion. The follow-up could be longer, however considering the favorable clinicopathologic findings (clinical stage T1c, organ-confined tumor, no Gleason 4 or 5, no positive surgical margins, and the minimal tumor extent, the probability of biochemical recurrence can be considered highly improbable.

These patients belong to the very low risk group for biochemical recurrence and could have been candidates for active surveillance. The study was based on a small number of patients. The low frequency of $4.2 \%$ for this group of patients submitted to radical prostatectomy was between $2.6 \%$ and 5.8\% of other studies (14-16) and in our study reflects the involvement of our Institution in proposing to patients with criteria for insignificant cancer, active surveillance instead of definitive treatment. Not all needle biopsies were extended 12-core. From the total of 17 needle biopsies, 12 were extended; the mean and median number of cores was 10 and 9. In case all needle biopsies were extended, results could have been different. Therefore, other studies with only extended biopsies and higher number of patients are needed to support our study. We must consider, however, that in Epstein's original 1994 study the median number of cores sampled was 5 and the results were valid in the contemporary analysis of 2011 with extended biopsies $(3,4)$.

\section{CONCLUSIONS}

From a total of 401 patients submitted to radical prostatectomy, 17 harbored insignificant cancer in the surgical specimen. Comparing the clinicopathologic fundings with Epstein's criteria on needle biopsies predictive of insignificant cancer, there was 100\% concordance for clinical stage T1c, no Gleason pattern 4 or 5, $\leq 2$ cores with cancer, and no single core with $>50 \%$ cancer. However, only $24 \%$ had density $\leq 0.15$.

We found that Epstein's criterion of "no single core with $>50 \%$ cancer" corresponded to $>2.5$ $\mathrm{mm}$ in linear extent. An additional finding was a maximum length not more than $3 \mathrm{~mm}$ considering all cores. This correspondence is important because many pathologists estimate linear extent in $\mathrm{mm}$ of cancer instead of percentage. To pathologists that use Epstein's criteria predictive of insignificant cancer and measure linear extent in mm, our study favors that "no single core with $>50 \%$ cancer" may correspond to $>2.5 \mathrm{~mm}$ in linear extent.

\section{CONFLICT OF INTEREST}

None declared.

\section{REFERENCES}

1. van den Bergh RC, Roemeling S, Roobol MJ, Roobol W, Schröder $\mathrm{FH}$, Bangma $\mathrm{CH}$. Prospective validation of active surveillance in prostate cancer: the PRIAS study. Eur Urol. 2007;52:1560-3. 
2. Montironi R, Egevad L, Bjartell A, Berney DM. Role of histopathology and molecular markers in the active surveillance of prostate cancer. Acta Oncol. 2011;50(Suppl 1):56-60.

3. Epstein JI, Walsh PC, Carmichael M, Brendler CB. Pathologic and clinical findings to predict tumor extent of nonpalpable (stage T1c) prostate cancer. JAMA. 1994;271:368-74.

4. Bastian PJ, Mangold LA, Epstein JI, Partin AW. Characteristics of insignificant clinical T1c prostate tumors. A contemporary analysis. Cancer. 2004;101:2011-5.

5. Berney DM, Algaba F, Camparo P, Comperat E, Griffiths D, Kristiansen $G$, et al. Variation in reporting of cancer extent and benign histology in prostate biopsies among European pathologists. Virchows Arch. 2014; 464:583-7.

6. Epstein JI, Allsbrook WC Jr, Amin MB, Egevad LL and the ISUP Grading Committee. The 2005 International Society of Urological Pathology (ISUP) consensus conference on Gleason grading of prostatic carcinoma. Am J Surg Pathol 2005; 29:1228-42.

7. Cookson MS, Aus G, Burnett AL, Canby-Hagino ED, D’Amico $\mathrm{AV}$, Dmochowski RR, et al. Variation in the definition of biochemical recurrence in patients treated for localized prostate cancer: the American Urological Association Prostate Guidelines for Localized Prostate Cancer Update Panel report and recommendations for a standard in the reporting of surgical outcomes. J Urol. 2007; 177:540-5.

8. Billis A, Magna LA, Ferreira U. Correlation between tumor extent in radical prostatectomies and preoperative PSA, histological grade, surgical margins, and extraprostatic extension: application of a new practical method for tumor extent evaluation. Int Braz $\mathrm{J}$ Urol. 2003; 29:113-9.

9. Van der Kwast T, Bubendorf L, Mazerolles C, Raspollini MR, Van Leenders GJ, Pihl CG, et al. Pathology Committee of the European Randomized Study of Screening for Prostate Cancer (ERSPC). Guidelines on processing and reporting of prostate biopsies: the 2013 update of the pathology committee of the European Randomized Study of Screening for Prostate Cancer (ERSPC). Virchows Arch. 2013; 463:367-77.

10. Harnden P, Shelley MD, Naylor B, Coles B, Mason MD. Does the extent of carcinoma in prostatic biopsies predict prostatespecific antigen recurrence? A systematic review. Eur Urol. 2008;54:728-39.

11. Montironi R, Scarpelli M, Mazzucchelli R, Cheng L, LopezBeltran A, Montorsi F. Extent of cancer of less than $50 \%$ in any prostate needle biopsy core: How many millimeters are there? Eur Urol 2012;61:751-6.

12. Karram S, Trock BJ, Netto GJ, Epstein Jl. Should intervening bening tissue be included in the measurement of discontinuous foci of cancer on prostate needle biopsy? Correlation with radical prostatectomy findings. Am J Surg Pathol 2011;35:1351-5.

13. Quintal MMQ, Meirelles LR, Freitas LLL, Magna LA, Ferreira $\mathrm{U}$, Billis A. Various morphometric measurements of cancer extent on needle prostatic biopsies: which is predictive of pathologic stage and biochemical recurrence following radical prostatectomy? Int Urol Nephrol 2011;43:697-705.

14. Sengupta S, Blute ML, Bagniewski SM, Inman B, Leibovich BC, Slezak JM, et al. After radical retropubic prostatectomy "insignificant" prostate cancer has a risk of progression similar to low-risk "significant" cancer. BJU Int. 2008;101:170-4.

15. Augustin H, Hammerer PG, Graefen M, Erbersdobler A, Blonski J, Palisaar J, et al. Insignificant prostate cancer in radical prostatectomy specimen: time trends and preoperative prediction. Eur Urol. 2003; 43:455-60.

16. Loeb S, RoehI KA, Thaxton CS, Catalona WJ. Combined prostatespecific antigen density and biopsy features to predict "clinically insignificant” prostate cancer. Urology. 2008; 72:143-7.

17. Dall'Era MA, Cooperberg MR, Chan JM, Davies BJ, Albertsen $\mathrm{PC}$, Klotz LH, et al. Active surveillance for early-stage prostate cancer: review of the current literature. Cancer. 2008; 112:16509 .

18. D’Amico AV, Cote $K$, Loffredo M, Renshaw AA, Schultz D. Determinants of prostate cancer-specific survival after radiation therapy for patients with clinically localized prostate cancer. J Clin Oncol. 2002; 20:4567-73.

19. Patel MI, DeConcini DT, Lopez-Corona E, Ohori M, Wheeler T, Scardino PT. An analysis of men with clinically localized prostate cancer who deferred definitive therapy. J Urol. 2004;171:1520-4.

20. Soloway MS, Soloway CT, Williams S, Ayyathurai R, Kava B, Manoharan M. Active surveillance; a reasonable management alternative for patients with prostate cancer: the Miami experience. BJU Int. 2008;101:165-9.

21. van As NJ, Norman AR, Thomas K, Khoo VS, Thompson A, Huddart RA, et al. Predicting the probability of deferred radical treatment for localised prostate cancer managed by active surveillance. Eur Urol. 2008;54:1297-305.

22. Ploussard G, Salomon L, Xylinas E, Allory Y, Vordos D, Hoznek $A$, et al. Pathological findings and prostate specific antigen outcomes after radical prostatectomy in men eligible for active surveillance-does the risk of misclassification vary according to biopsy criteria? J Urol. 2010;183:539-45.

23. Freedland SJ, Kane CJ, Presti JC Jr, Terris MK, Amling CL, Dorey $\mathrm{F}$, et al. Comparison of preoperative prostate specific antigen density and prostate specific antigen for predicting recurrence after radical prostatectomy: results from the search data base. $J$ Urol. 2003;169:969-73.

Correspondence address:

Athanase Billis, MD

Department of Anatomic Pathology School of Medical Sciences State University of Campinas (Unicamp)

Rua Tessália Vieira de Camargo, 126 Campinas, SP,13083-887, Brazil Fax: + 5519 3289-3897

E-mail: athanase@fcm.unicamp.br 